\title{
Pengembangan Bagan Kendali 3 Sigma Berbasis Simulasi Untuk Pengawasan Variabilitas Proses Multivariat
}

\author{
Rahmat Sagara'), Khoirul Umam²) \\ Program Studi Matematika, Fakultas Bisnis Institut Teknologi dan Bisnis Kalbis \\ Jalan Pulomas Selatan kav.22, Jakarta Timur 13210 \\ ${ }^{1)}$ Email: rahmat.sagara@kalbis.ac.id \\ ${ }^{2)}$ Email: khoirul.umam@kalbis.ac.id
}

\begin{abstract}
This article describes a method in developing control charts for generalized variance as a quality statistics in terms of process variability through simulation. Mathematical equation that maps sample size $n$ and number of quality variables $p$ onto constant multiplier of standard deviation $K$ is obtained thorough least square method using simulated data. The constant $K$ for a certain $n$ and $p$ is used for control charts with the upper control limits of $U C L=\mu+K \sigma$ where $\mu$ and $\sigma$ are the mean and the standard deviation of the generalized variance, respectively. The simulation of finding the constant $K$ is used with the constraint of 3 sigma paradigm.
\end{abstract}

Keywords: control chart, generalized variance, simulation, 3 sigma paradigm

\begin{abstract}
Abstrak: Artikel ini memaparkan sebuah metode pengembangan bagan kendali untuk generalized variance sebagai sebuah statistik mutu yang berkaitan dengan variabilitas proses menggunakan simulasi. Persamaan matematika yang mengaitkan ukuran sampel $n$ dan banyaknya variabel mutu $p$ terhadap konstanta pengali standar deviasi $K$ didapatkan melalui metode kuadrat terkecil menggunakan data simulasi. Konstanta $K$ yang didapatkan untuk suatu nilai $n$ dan $p$ kemudian digunakan untuk bagan kendali dengan batas kendali atas $U C L=\mu+K \sigma$ dimana $\mu$ dan $\sigma$ masing-masing adalah rata-rata dan standar deviasi dari generalized variance. Simulasi pencarian K ini dilakukan dengan kendala memenuhi paradigma 3 sigma.
\end{abstract}

Kata kunci: bagan kendali, generalized variance, paradigma 3 sigma, simulasi

\section{PENDAHULUAN}

Bentuk umum dari bagan kendali adalah

$$
\begin{gathered}
\text { UCL }=\mu+K \sigma \\
C L=\mu \\
\text { LCL }=\mu-K \sigma
\end{gathered}
$$

dimana $\mu$ dan $\sigma$ masing-masing adalah ratarata dan standar deviasi dari statistik mutu yang digunakan. Dengan mengadopsi paradigma 3 sigma bahwa dari sejuta produk yang dihasilkan hanya 2700 produk yang cacat [1], konstanta $\mathrm{K}$ bernilai 3 jika distribusi dari statistik mutu tersebut adalah normal berdasarkan fakta bahwa jika variabel acak $\mathrm{X} \sim \mathrm{N}\left(\mu, \sigma^{2}\right)$ maka

$\mathrm{P}(\mathrm{X}<\mu-3 \sigma$ atau $\mathrm{X}>\mu+3 \sigma) \cong 0.002700$

atau

$$
\mathrm{P}(\mathrm{X}<\mu-3 \sigma)=\mathrm{P}(\mathrm{X}>\mu+3 \sigma) \cong 0.00135
$$

Konstanta $\mathrm{K}$ tidak sama dengan 3 jika statistik mutu tidak berdistribusi normal, namun dekat dengan 3 jika statistik mutu berdistribusi normal asimtotis - berdistribusi normal jika ukuran sampel menuju tak hingga. Sebagai contoh untuk statistik mutu generalized variance dan vector variance, [2] memperlihatkan bahwa ketika $\mathrm{K}=3$ maka nilai PFA (probability of a false alarm) jauh dari angka 0.002700 meskipun untuk $\mathrm{n}=100$.

Untuk mencari nilai $\mathrm{K}$ yang lebih baik, [2] melakukan simulasi untuk ukuran sampel $\mathrm{n}=5$, 20 , dan 100 dan banyaknya variabel $p=3$. Dengan menggunakan metode simulasi serupa, pada artikel ini akan dibahas pencarian konstanta $\mathrm{K}_{\mathrm{p}}$ yang diekspresikan sebagai sebuah fungsi $K_{p}=f(n)$ untuk statistik mutu generalized variance.

\section{METODE PENELITIAN}

Misalkan $\overrightarrow{\mathrm{X}}_{1}, \overrightarrow{\mathrm{X}}_{2}, \cdots, \overrightarrow{\mathrm{X}}_{\mathrm{n}}$ sebuah sampel acak berukuran $\mathrm{n}$ dari populasi berdistribusi normal 
multivariat $\mathrm{N}_{\mathrm{p}}(\vec{i}, \Sigma)$ dimana $\vec{i}$ adalah vektor ratarata dan $\Sigma$ adalah matriks kovariansi populasinya. Misalkan pula $S$ adalah matriks kovariansi sampelnya. Maka (lihat [3]) distribusi eksak dari generalized variance $|\mathbf{S}|$ sama dengan distribusi dari statistik

$$
\frac{|\mathbf{O}|}{(\mathrm{n}-1)^{\mathrm{p}}} \sum_{\mathrm{k}=1}^{\mathrm{p}} \mathrm{Z}_{\mathrm{k}}
$$

dimana variabel acak $Z_{1}, Z_{2}, \cdots, Z_{p}$ saling bebas dan masing-masing berdistribusi $\div^{2}$ dengan derajat kebebasan n-1, n-2, $\cdots$, n-p. Dengan demikian, (lihat [4]), didapatkan bahwa

$$
\begin{aligned}
& E[|S|]=\mathrm{b}_{1}|\Sigma| \text { dan } \operatorname{Var}[|S|]=\mathrm{b}_{2}|\Sigma|^{2} \\
& \mathrm{~b}_{1}=\frac{1}{(\mathrm{n}-1)^{\mathrm{p}}} \prod_{\mathrm{k}=1}^{\mathrm{p}}(\mathrm{n}-\mathrm{k}) \\
\mathrm{b}_{2}= & \frac{1}{(\mathrm{n}-1)^{\mathrm{p}}} \prod_{\mathrm{k}=1}^{\mathrm{p}}(\mathrm{n}-\mathrm{k}) \times\left(\prod_{\mathrm{j}=1}^{\mathrm{p}}(\mathrm{n}-\mathrm{j}+2)-\prod_{\mathrm{i}=1}^{\mathrm{p}}(\mathrm{n}-\mathrm{i})\right)
\end{aligned}
$$

Sedangkan distribusi asimtotis dari generalized variance (lihat [4]) adalah

$$
\frac{1}{\sqrt{\mathrm{b}_{2}}}\left(|\mathbf{S}|-\mathrm{b}_{1} \mid \mathbf{\mathbf { O }}\right) \underset{\rightarrow}{\operatorname{d} \mathrm{N}}\left(\rho \mid \mathbf{O}^{2}\right)
$$

Karena $E[|S|]=b_{1}|\Sigma|$ dan $\operatorname{Var}[|S|]=b_{2}|\Sigma|^{2}$ maka bagan kendali untuk generalized variance $|S|$ adalah

$$
\begin{aligned}
& U C L=b_{1}\left|\sum\right|+K_{p}{\sqrt{b_{2}\left|\sum\right|^{2}}}^{2} \\
& C L=b_{1}\left|\sum\right|
\end{aligned}
$$

dimana $\mathrm{K}_{\mathrm{p}}$ merupakan konstanta pengali yang berkaitan dengan $\mathrm{p}$ dan merupakan fungsi dari ukuran sampel $\mathrm{n}$ serta memenuhi paradigma 3 sigma, yaitu bahwa:

$$
\mathrm{P}\left(|\mathbf{S}|>\mathrm{b}_{1}|\mathbf{\phi}|+\mathrm{K}_{\mathrm{p}} \sqrt{\mathrm{b}_{2} \mid \mathbf{\phi}^{2}}\right) \cong 0.00135
$$

\section{A. Simulasi}

Tanpa mengurangi keumuman, simulasi dilakukan menggunakan data hasil pembangkitan dari populasi normal multivariat dengan vektor rata-rata vektor nol dan matriks kovariansi matriks identitas. Algoritma untuk menentukan nilai $\mathrm{K}_{\mathrm{p}}$ ini adalah sebagai berikut: 1) Untuk suatu nilai $\mathrm{p}$, bangkitkan 100000 (seratus ribu) data berukuran $n$ dari populasi berdistribusi $\left.\mathrm{N}_{\mathrm{p}}(\overrightarrow{0}, \mathbf{I}) ; 2\right)$ Untuk masingmasing matriks data berukuran $\mathrm{n} \times \mathrm{p}$ itu, hitung nilai dari generalized variance yaitu determinan dari matriks kovariansi sampel; 3) Urutkan ke 100000 nilai generalized variance itu dari kecil ke besar; 4) Dapatkan Q, yaitu nilai generalized variance urutan ke 99865; dan 5) Dapatkan konstanta $\mathrm{K}_{\mathrm{p}}$ dengan formula: $\mathrm{K}_{\mathrm{p}}=\frac{\mathrm{Q}-\mathrm{b}_{1}}{\sqrt{\mathrm{b}_{2}}}$

\section{B. Hasil simulasi}

Hasil simulasi konstanta pengali untuk $\mathrm{p}=2$, $3,5,10,15,20$ dan $\mathrm{n}=25,50,100,250,500,1000$ disajikan pada Tabel 1.

Tabel 1 Hasil Simulasi Konstanta Pengali
\begin{tabular}{|c|c|c|c|c|c|c|c|}
\hline \multicolumn{2}{|c|}{$\mathrm{p}$} & 2 & 3 & 5 & 10 & 15 & 20 \\
\hline \multirow{5}{*}{$\mathrm{n}$} & 25 & 4.44183 & 5.08007 & 6.08987 & 8.08241 & 9.8437 & 9.84422 \\
\cline { 2 - 9 } & 50 & 4.02038 & 4.38765 & 5.04556 & 6.54118 & 7.38947 & 8.21068 \\
& 100 & 3.70155 & 3.98221 & 4.35005 & 5.18595 & 5.99643 & 6.47568 \\
\cline { 2 - 9 } & 250 & 3.47854 & 3.64598 & 3.81005 & 4.27615 & 4.71758 & 4.99328 \\
\cline { 2 - 9 } & 500 & 3.2566 & 3.42571 & 3.59104 & 3.89642 & 4.10858 & 4.24538 \\
\hline & 1000 & 3.20954 & 3.32293 & 3.37985 & 3.58576 & 3.67614 & 3.99297 \\
\hline
\end{tabular}

\section{Perumusan Model}

Untuk suatu nilai $\mathrm{p}$, hasil simulasi pasangan terurut $\left(\mathrm{n}, \mathrm{K}_{\mathrm{p}}\right)$ untuk $\mathrm{n}=25,50,100,250,500$, dan 1000 digambarkan diagram plotnya dan ditentukan model persamaan $\mathrm{K}_{\mathrm{p}}$ sebagai fungsi dari $\mathrm{n}$.

Sebagai contoh, untuk banyaknya variabel $\mathrm{p}=$ 5 dan ukuran sampel $\mathrm{n}=25,50,100,250,500$, dan 1000 didapatkan plot pasangan terurut $\left(n, \mathrm{~K}_{5}\right)$ sebagai mana disajikan pada Gambar 1.

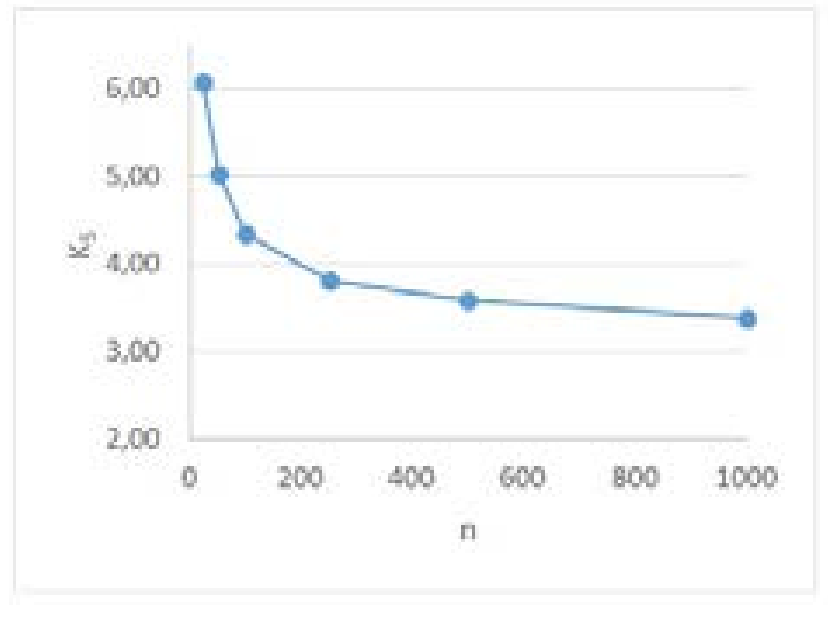

Gambar 1 Plot hubungan $n$ dan $K_{5}$

Gambar 1 memperlihatkan bahwa $\mathrm{K}_{5}$ berbanding terbalik dengan $\mathrm{n}$, dan karena generalized variance berdistribusi normal asimtotis maka $\mathrm{K}_{5} \rightarrow 3$ jika $\mathrm{n} \rightarrow \infty$ Oleh karena itu model hubungan $\mathrm{n}$ dan $\mathrm{K}_{5}$ bisa dirumuskan melalui persamaan

$$
K_{5}=3+A n^{-B}
$$

dengan A dan B adalah dua konstanta positif.

\section{HASIL DAN PEMBAHASAN}

Pandang kembali model hubungan $\mathrm{n}$ dan $\mathrm{K}_{5}$ dalam persamaan

$$
K_{5}=3+A n^{-B}
$$

dimana A dan B adalah dua konstanta positif. Pada bagian ini, akan dicari taksiran dari A dan B menggunakan data konstanta pengali $\mathrm{K}_{5}$ dari hasil simulasi pada Tabel 1. 
Persamaan 1 ekivalen dengan persamaan

$$
K_{5}-3=A n^{-B}
$$

Penerapan fungsi logaritma natural pada kedua sisi Persamaan 2 mendapatkan

$$
\ln (K-3)=\ln A-B \ln n
$$

sehingga didapatkan hubungan linier antara $\mathrm{h}\left(\mathrm{K}_{5}-3\right)$ dan $\mathrm{h}(\mathrm{n})$.

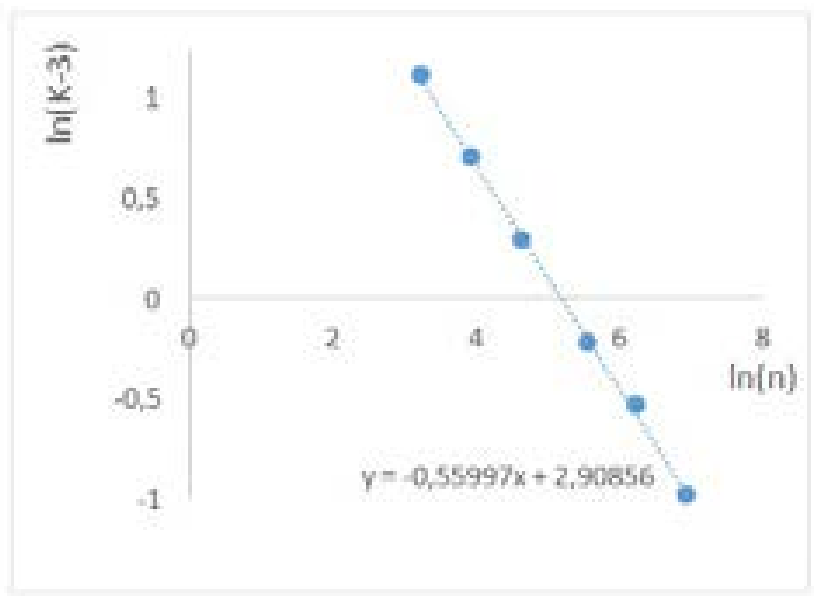

Gambar 2 Hubungan linier $\ln \left(\mathrm{K}_{5}-3\right)$ dan $\ln (\mathrm{n})$

Dengan menggunakan metode kuadrat terkecil didapatkan taksiran $\mathrm{h}(\mathrm{A})=2.908563$ atau $\mathrm{A}=18.33043$, dan $\mathrm{B}=0.55997$. Dengan demikian, untuk $\mathrm{p}=5$, konstansa pengali $\mathrm{K}_{5}$ sebagai fungsi dari $\mathrm{n}$ dituliskan sebagai berikut

$$
\mathrm{K}_{5}(\mathrm{n})=3+18.33043 \mathrm{n}^{-0.55997}
$$

Menggunakan prosedur yang sama, untuk $\mathrm{p}=2$, $3,5,10,15,17$, dan 20 didapat taksiran untuk A dan B seperti disajikan pada Tabel 2.

Tabel 2 Taksiran nilai untuk $A$ dan B

\begin{tabular}{ccc}
\hline $\mathbf{P}$ & $\mathbf{A}$ & $\mathbf{B}$ \\
\hline 2 & 8.36591 & 0.53896 \\
3 & 10.25519 & 0.50514 \\
5 & 18.33043 & 0.55997 \\
10 & 33.99401 & 0.58872 \\
15 & 50.61895 & 0.61861 \\
20 & 42.73245 & 0.55325 \\
\hline
\end{tabular}

\section{SIMPULAN}

Pada paper ini sudah dipaparkan mengenai pengembangan bagan kendali 3 sigma berbasis simulasi untuk pengawasan variabilitas proses multivariat menggunakan general variance dengan hasil sebagai berikut.
Bagan kendali berupa

$$
\begin{aligned}
& U C L=b_{1}\left|\sum\right|+K_{p}{\sqrt{b_{2} \mid \Sigma}}^{2} \\
& C L=b_{1}\left|\sum\right|
\end{aligned}
$$

dimana

Óadalah matriks definit positif berukuran $p \times p$ yang ditargetkan sebagai matriks kovariansi populasi,

$$
\begin{aligned}
& \mathrm{b}_{1}=\frac{1}{(\mathrm{n}-1)^{\mathrm{p}}} \prod_{\mathrm{k}=1}^{\mathrm{p}}(\mathrm{n}-\mathrm{k}) \\
& \mathrm{b}_{2}=\frac{1}{(\mathrm{n}-1)^{\mathrm{p}}} \prod_{\mathrm{k}=1}^{\mathrm{p}}(\mathrm{n}-\mathrm{k}) \times\left(\prod_{\mathrm{j}=1}^{\mathrm{p}}(\mathrm{n}-\mathrm{j}+2)-\prod_{\mathrm{i}=1}^{\mathrm{p}}(\mathrm{n}-\mathrm{i})\right) \\
& \mathrm{K}_{\mathrm{p}} \text { adalah konstanta pengali yang berkaitan }
\end{aligned}
$$
dengan $\mathrm{p}$ dan merupakan fungsi dari ukuran sampel $\mathrm{n}$ yang dirumuskan sebagai $K_{p}=3+A n^{-B}$ dengan nilai A dan $B$ kedua-duanya bilangan positif.

Konstanta pengali $\mathrm{K}_{\mathrm{p}}$ nilainya dipengaruhi oleh $\mathrm{p}$ selain dipengaruhi oleh $\mathrm{n}$. Dengan demikan konstanta pengali merupakan sebuah fungsi dari dua variabel $p$ dan n. Akan tetapi pada penelitian ini belum kepada pencarian bentuk eksplisit $\mathrm{K}=\mathrm{f}(\mathrm{p}, \mathrm{n})$. Diharapkan, pada penelitian selanjutnya didapat model hubungan eksplisit konstanta pengali $\mathrm{K}$ sebagai fungsi dua variabel dari $\mathrm{p}$ dan $\mathrm{n}$ tersebut.

\section{DAFTAR RUJUKAN}

[1] D. C. Montgomery, Introduction to Statistical Quality Control, New York: John Wiley \& Sons, 2009, p. 29.

[2] M. A. Djauhari, R. M. Salleh, Z. Zolkeply dan L. S. $\mathrm{Li}$, "On the reliability of Shewhart-type control charts for multivariate process variability," AIP Conference Proceedings, vol. 1842, no. 1, pp. 030028-6, 2017.

[3] M. A. Djauhari, "Improved monitoring of multivariate process variability," Journal of Quality Technology, vol. 37, no. 1, p. 33, 2005.

[4] M. A. Djauhari, Advanced Monitoring Techniques for Complex Process Variability in Manufacturing Industry, Serdang: Universiti Putra Malaysia Press, 2016, pp. 13-15, 21. 